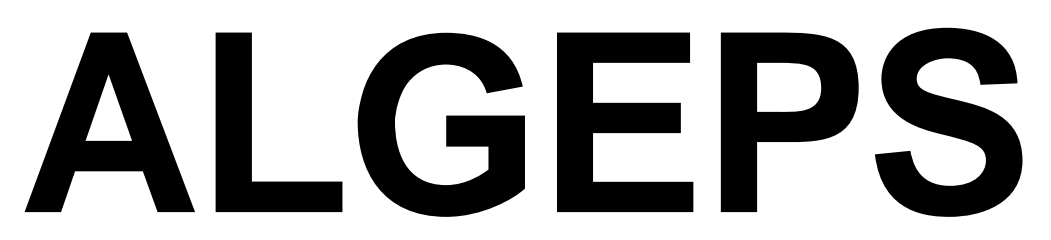

REVISTA DE GEOLOGIA, SÈRIE B $n^{\circ} 611$ - Desembre del 2012

ISSN $1132-7014$

D.L.B. 28.178 - 92

11 pàgines

\title{
RECORREGUT DE RECERCA GEOLÒGICA I MINERALÒGICA PER LA COMARCA DEL PRIORAT: DES DEL COLL DE LA TEIXETA I PRADELL A FALSET I A BELLMUNT DEL PRIORAT
}

Josep M. Mata-Perelló i Joaquim Sanz Balagué 


\section{RECORREGUT DE RECERCA GEOLÒGICA I MINERALÒGICA PER LA COMARCA DEL PRIORAT: DES DEL COLL DE LA TEIXETA I PRADELL A FALSET I A BELLMUNT DEL PRIORAT / 12A DE GENER DEL 2011}

Per Josep M. MATA-PERELLÓ i Joaquim SANZ i BALAGUÉ

\section{ADVERTIMENTS PREVIS}

Com en altres recorreguts de RECERCA GEOLÒGICA I MINERALÒGICA ..., si es disposa del temps suficient, poden efectuar-se passant per totes les parades i filloles. En cas contrari, recomanem prescindir de les anomenades PARADES - CONDICIONALS.

També cal demanar. abans de començar el recorregut de l'itinerari, quin es l'estat de les pistes i dels camins per on discorrerà, en algun dels seus trams. En aquest itinerari, es transitarà per camins no gaire bons per tal d'anar a la Guixera de Pradell o a la Mina de Pinyana (Falset). En algun cas, es situaran en aquests trams PARADES CONDICIONALS, en funció dels vehicles que facin els recorreguts.

Per d'altra banda, recomanem tenir una cura extrema de la NATURA, evitant qualsevol forma d'agresió sobre ella, o de fer-n'hi un mal ús del que en ofereix la nostra mare Terra.

\section{BREU INTRODUCCIÓ}

En aquesta ocasió, el recorregut del present itinerari discorrerà íntegrament, per una sola de les tres unitats geològiques que constitueixen Catalunya: concretament per la coneguda com a Sistema Mediterrani. Dintre d'aquesta, el recorregut recalarà, també exclusivament en una sola de les seves sotsunitats, concretament per la Serralada Prelitoral Catalana, (la més externa de totes).

Així, el recorregut s'iniciarà al Coll de Teixeta, dintre ja de l'esmentada Serralada Prelitoral Catalana, per la qual anirà circulant fins a la fi del recorregut de l'itinerari, fins arribar a Bellmunt del Priorat.

Per d'altra banda, aquest itinerari discorrerà per una sola comarca: la del Priorat, des dels voltants del Coll de Teixeta Falset a Bellmunt del Priorat, on clourà el recorregut del mateix. 


\section{OBJECTIUS FONAMENTALS}

Al llarg del present recorregut, si d'escau, s'intentaran aconseguir el següents objectius fonamentals.

1.- Estudi i observació dels materials paleozoics (del Carbonífer, fonamentalment). que constitueixen la Serralada Prelitoral Catalana, entre els quals discorrerà la major part del recorregut de l'itinerari.

2.- Estudi i observació dels materials mesozoics (del Triàsic exclusivament), que formen part de la Serralada Prelitoral Catalana, dintre del recorregut de l'itinerari, especialment pels voltants de Pradell de la Teixeta i de Bellmunt del Priorat.

3.- Estudi de diverses mineralitzacions situades entre els materials paleozoics i mesozoics de la Serralada Prelitoral. Entre aquestes, farem esment de les següents, d'acord amb l'ordre de desenvolupament del recorregut:

3A) de les mineralitzacions evaporítiques (de caràcter guixòs) que veurem pels voltants de Pradell de la Teixeta, entre els afloraments mesozoics del Muschelkalk Mig.

3B) de mineralitzacions filonianes de $\mathrm{Pb}-\mathrm{Zn}$..., que trobarem a diversos indrets del Priorat, i en especial pels antics termes miners de Falset i Bellmunt del Priorat, encaixades entre els materials del Carbonífer.

4.- Observació d'algunes explotacions subterrànies mineres antigues, com les situades als indrets esmentats dintre de l'apartat anterior, ubicades dintre de la Serralada Prelitoral Catalana. I també de les actuals explotacions de sauló ubicades al terme de Falset.

5.- Observació de les tasques de restauració, si s'escau, efectuades sobre les explotacions anteriors.

6.- Observació dels diferents indrets relacionats amb el Patrimoni Geològic i Miner, que es vagin trobant al llarg del present itinerari, com per exemple dels antics castellets miners situats a les antigues mines de Bellmunt del Priorat (Mina Renàlia, Mina Règia, Mina Lagarto), entre altres indrets del nostre Patrimoni Geològic i Miner, els quals podrien constituir per si sols un dels denominats territoris miners.

\section{ANTECEDENTS BIBLIOGRÀFICS}

Tot i que hi ha molts antecedents, d'altres itineraris que discorren per indrets coincidents en part amb el que ara presentem (MATA-PERELLÓ, 1996, 1997, 1998a, 1998b, 1998c, 1998d, 1999, 2000a, 2000b, 2001, 2002, 2007, 2008a i 2008b), no n'hi cap que coincideixi totalment amb el que ara volem presentar, a excepció del darrer, molt coincident en diferents indrets. Tret d'aquests, no coneixem cap altre itinerari d'aquest tipus que discorri per aquests indrets.

Pel que fa als antecedents bibliogràfics relatius a les mineralitzacions que veurem al llarg del recorregut, cal fer esment d'un interessant treball; concretament de MELGAREJO i DRAPER (1992), referit a les diferents mineralitzacions de les comarques 
reusenques. Un altre antecedent es troba en MATA-PERELLÓ (1991), referit a les mineralitzacions del conjunt dels Països Catalans. Tanmateix, també farem esment de CANALS (1985).

Pel que fa als trets de la geologia d'aquestes comarques, ens referirem de nou al treball de MELGAREJO i DRAPER (1992); així com a les publicacions de l'IGME (1974, 1978a, 1978b i 1978c). Per d'altra banda, també farem esment de dos treballs referits al conjunt dels Països Catalans. Es tracta dels de: GUIMERÀ et altri (1992) i de RIBA et altri (1979).

Tots aquests treballs esmentats, i d'altres, figuraran per ordre alfabètic a l'apartat dedicat a les REFERÈNCIES BIBLIOGRÀFIQUES.

\section{DESCRIPCIÓ DEL RECORREGUT DE L'ITINERARI}

El recorregut del present itinerari començarà a les immediacions del Coll de Teixeta, per on es farà una aturada. Tot seguit s'anirà cap al poble Pradell de la Teixeta, per on es farà una altra aturada prop de l'antiga guixera (tant a l'explotació com a la fàbrica de Guix). Després, a través de la carretera N-420 anirem cap a Falset, fent una aturada al Coll de Falset.

Després, des de Falset, ens caldrà agafar la carretera local que es dirigeix cap a la propera població de Bellmunt del Priorat, fent una fillola per anar a la Mina de Pinyana (del terme de Falset), Més endavant es pararà a l'explotació de sauló, situada a la mateixa carretera.

Seguidament es continuarà cap a Bellmunt del Priorat, poc abans d'arribar-hi es farà una parada a l'antiga Mina Renàlia. En arribar al poble, es faran les aturades a diferents indrets (Mina Regia I i Mina Regia II o Antiga). Aquí finalitzarà aquest recorregut.

\section{DESCRIPCIÓ DE L'ITINERARI}

Com de costum, estructurarem el recorregut de l'itinerari en una sèrie de PARADES, que tot seguit anirem veient. En cada una d'aquestes aturades farem un breu comentari (geològic o mineralògic, segons śescaigue).

En cada cas indicarem, entre parèntesi el full topogràfic del "Mapa Topogràfico Nacional" a escala 1:50.000 on es troba l'aturada, que en aquest cas serà sempre algun dels següents dos fulls: 471 (dit també de Mora) i $\mathbf{4 7 2}$ (dita de Reus). Aquests fulls han estat publicats per l'Instituto Geografico y Catastral de España.

Així doncs, la relació ordenada de les aturades que composen aquest itiunerari, és la següent: 
PARADA 1. COLL DE LA TEIXETA, (terme de Duesaigües, comarca del Baix Camp (Full 445).

El recorregut del present itinerari començarà en aquest indret, situat a la cruïlla entre les carreteres a Rudecols, Porrera, Falset i Riudecanyes, prop del límit entre les comarques del Baix Camp i del Priorat.

Així, en aquest indret es fa ben palesa la discordança entre els materials triàsics del Buntsandsteim (constituïts per nivells de gresos i de lutites rogenques, que descansen sobre nivells de conglomerats quarsosos), i els materials del Carbonífer (formats per nivells de pissarres). Per d'altra banda, entre els materials del Buntdsandsteim es fa ben palesa l'erosió alveolar, amb bons exemples de la mateixa, situant-se entre els nivells dels gresos rogencs.

Finalment, direm que des d'aquest indret, i mirant cap a llevant, es poden veure una sèrie de pedreres, en les quals s'extreien carreus de granodiorites. Una d'aquestes pedreres, també es troba en la banda de la carretera procedent de Duesaigües.

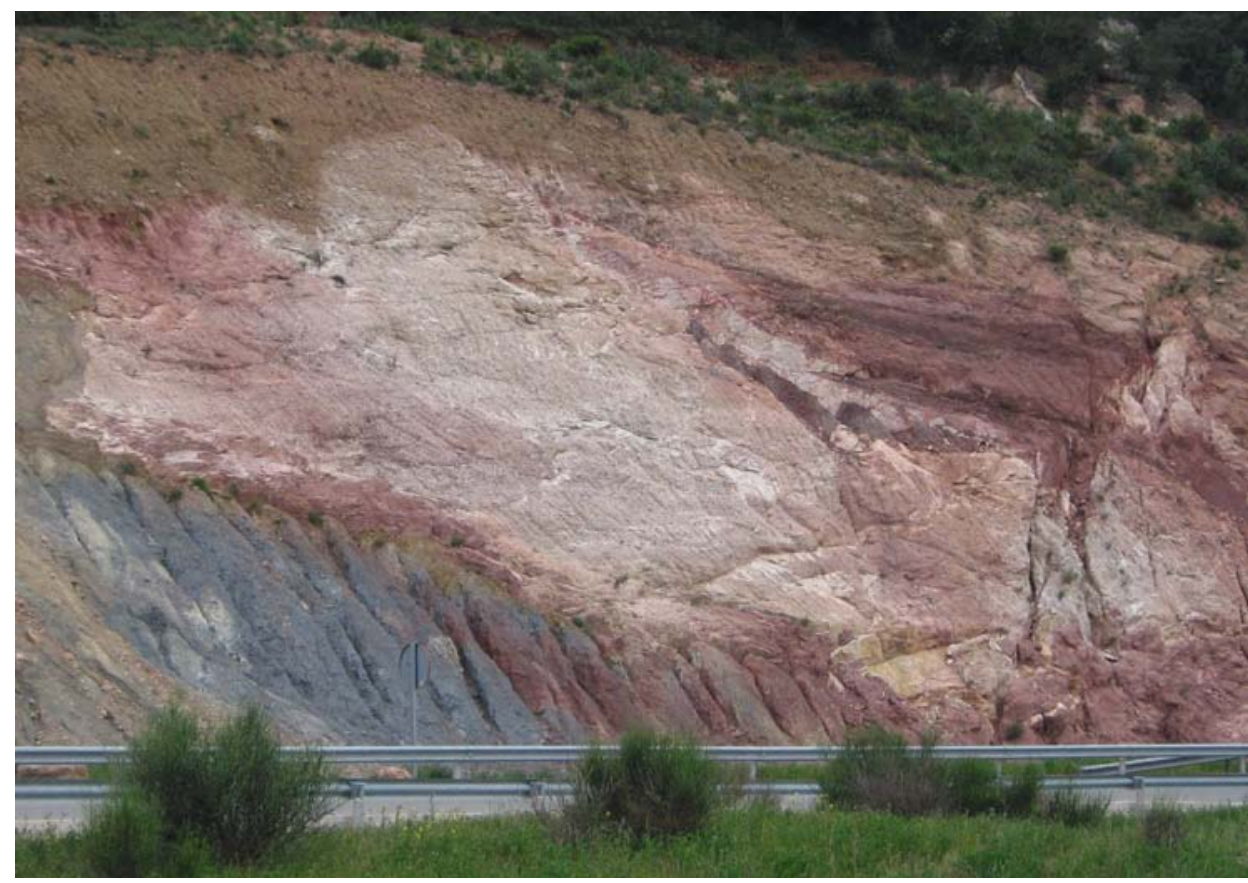

FOTOGRAFIA 1. Un aspecte de la Falla del Coll de la Teixeta

PARADA 2. GUIXERA DE PRADELL DE LA TEIXETA, (terme de Pradell de la Teixeta, comarca del Priorat). (Full 472).

Després de fer l'aturada anterior, cal seguir l'itinerari cap a ponent, per la carretera $\mathrm{N}-240$, la qual es dirigeix cap a Falset. En arribar al trencall d'on surt la carretera que mena cap a Pradell de la Teixeta, la TV-2332 (la qual es dirigeix cap a la Torre de la Fontaubella), ens caldrà agafar-la. Després de sobrepassar Pradell, a uns $2 \mathrm{Km}$ de la població, caldrà continuar per un camí (cap a l'esquerra), el qual arriba fins a les antigues guixeres, on farem una nova aturada d'aquest itinerari. 
En aquest recorregut, hem anat travessant afloraments dels materials carbonatats (calcaris i dolomítics), els quals pertanyen al Muschelkalk Inferior. Tanmateix, hem trobat afloraments de nivells argilosos del Muschelkalk Mig. Uns i altres pertanyen al Triàsic Mig de la Serralada Prelitoral Catalana, per on estem ara situats.

En aquest lloc hi ha una antiga explotació dels nivells de guixos triàsics (del Muschelkalk Mig). A l'actualitat l'explotació de la guixera es troba totalment aturada, i sovint s'utilitza per a tirar-hi runes i residus. Els materials extrets en aquest indret s'utilitzaben com a matèria prima de la fàbrica de guix que veurem a la parada següent.

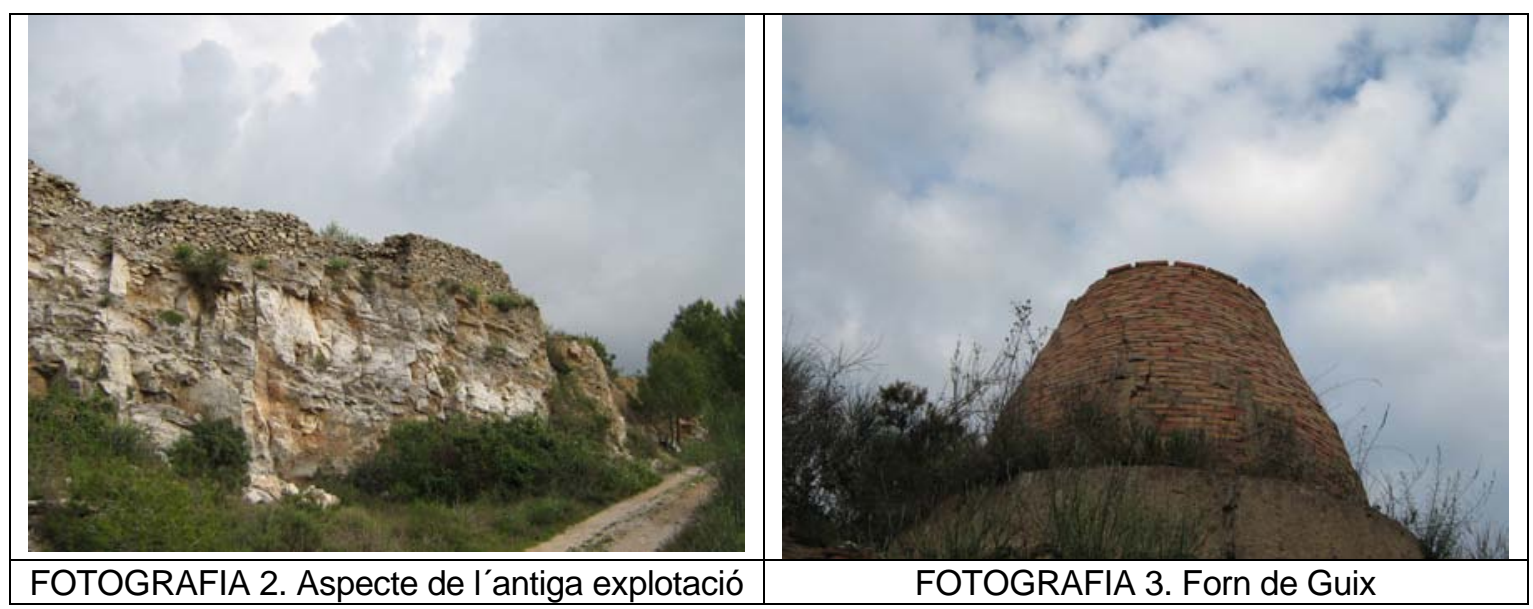

Finalment, cal dir que aquesta guixera es troba situada sota d'un dels parcs eòlics de la zona, i molt fàcilment es pot sentir la fresa de les aspes al rodollar.

\section{PARADA 3. ANTIGA FÀBRICA DE GUIX, (terme de Pradell de la Teixeta, comarca del Priorat). (Full 472).}

Des de la parada anterior cal retrocedir a Pradell de la Teixeta, per tal de continuar després cap a la carretera nacional N-420. Poc abans d'arribar-hi, es trobarà l'antiga fàbrica de guix situada a la vora de la carretera. Aquí farem una nova aturada, després de recórrer uns 3’5 Km des l'aturada anterior.

En aquest lloc es treballaven els materials guixosos extrets a la guixera de la parada anterior, per tal d'obtenir guix industrial per a la construcció. A l'actualitat (a l'igual que la guixera) es troba totalment aturada.

Finalment, cal dir que aquest element industrial forma part del nostre patrimoni miner, mereixent una certa protecció.

PARADA 4 - CONDICIONAL. COLL DE FALSET, (terme municipal de Falset, comarca del Priorat). (Full 472).

Després de realitzar la parada anterior, cal retornar a la carretera $N-420$, per tal de continuar cap a ponent. Per ella, cal arribar fins al Coll de Falset, on realitzarem la present aturada, després de recórrer uns $3 \mathrm{Km}$ més. 
En aquest recorregut, després de retornar a la carretera haurem continuat tallant els materials del Triàsic. Així, primer haurem trobat els del Muschelkalk Mig, i després els del Superior. Finalment es trobaran els materials rogencs del Keuper. Aquests darrers materials són els que es troben al Coll de Falset, on afloren els nivells de lutites rogenques, així com els característics guixos

Precisament, aquí on ara som, aquests materials es troben en contacte per falla amb els nivells carbonatats del Muschelkalk Inferior. Aquesta falla es fa força palesa al Nord del coll.

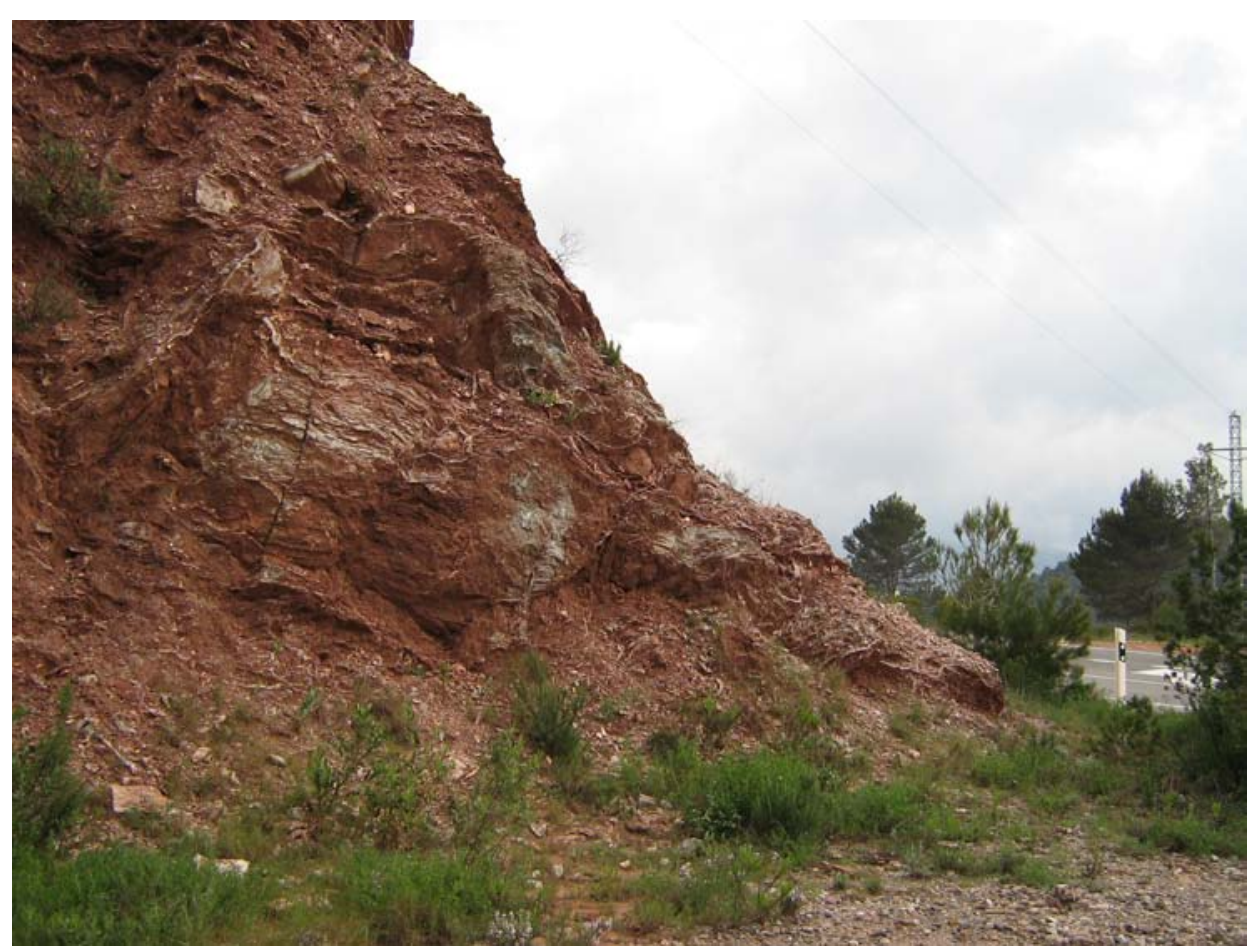

FOTOGRAFIA 4. Guixos rojos del Coll de Falset

PARADA 5. TRAM DE LA CARRETERA NACIONAL N-420, SITUAT ENTRE ELS Km 843’2 I EL Km 842'9, (terme municipal de Falset, comarca del Priorat). (Full 472).

Després de realitzar la parada anterior, cal continuar cap a ponent, tot seguint sempre la carretera nacional N-420. Per ella, cal arribar cap a les immediacions del Km 8432, per tal de fer la present aturada, després de recórrer uns $1^{\prime} 5 \mathrm{Km}$, des de la parada anterior.

En aquest breu recorregut, hem anat tallant els materials del Triàsic Superior (del Keuper), ja esmentats a la parada anterior realitzada al Coll de Falset, on afloren els nivells de lutites rogenques, així com els característics guixos. Més endavant, s’han començat a tallar els nivells carbonatats del Muschelkalk Inferior esmentats a la parada anterior; i tanmateix, més avall, poc abans d'arribar al Km 843'2 de la carretera anteriorment esmentada, es troben uns nivells rogencs (amb gresos i calcolutites) que pertanyen al Triàsic Inferior (al Buntsandsteim). Més avall, es troba el contacte discordant entre el 
Triàsic Inferior i el Carbonífer, dintre de la Serralada Prelitoral, això succeeix prop del Km $843^{\prime} 2$.

Per d'altra banda al Km. 842,9 de la mateixa carretera, (molt a prop ja de Falset) comencen a aflorar els materials granítics d'edat carbonífera. Aquests materials afloren extensament entre les localitats de Falset, Marcà i Masroig, fonamentalment.

\section{PARADA 6. MINES DE PLOM I D“ARGENT DE PINYANA, (terme municipal de Falset, comarca del Priorat). (Full 471).}

Des de la parada anterior, cal continuar per la carretera N-420 per tal d'arribar a Falset. Després a la sortida d'aquest poble, cal agafar la carretera local que condueix cap a Bellmunt del Priorat, la carretera local TP-7101.

Més endavant, en arribar a la Venta del Pinar, cal agafar un camí, per l'esquerra, que en $1 \mathrm{Km}$ es dirigeix a les Mines de Pinyana. Aquí, i després d'un recorregut proper als $6 \mathrm{Km}$, des de la parada anterior, cal fer la present aturada.

En aquest recorregut, hem anat trobant afloraments de granits i de granodiorites. Tots aquests materials són els que trobem entorn a la població de Falset, i també en el recorregut cap a l'indret de la parada, a les Mines de Pinyana. on ara ens trobem.

En aquest indret hi ha unes antigues mines, les quals beneficiaven unes mineralitzacions filonianes, fonamentalment de $\mathrm{Pb}-\mathrm{Zn}$, encaixades entre els porfirs granítics que tallen als materials carbonífers. Aquestes mineralitzacions es relaciones amb una important fractura, de direcció ENE-WSW. Així, sovint la mineralització te aspecte bretxoide.

Entre els minerals presents, cal fer esment dels següents: CALCOPIRITA, ESFALERITA, GALENA, MARCASSITA i PIRITA. Entre els minerals d'alteració es troben: GOETHITA (terrosa i limonítica), ATZURITA, CERUSSITA, HIDROCINCITA, MALAQUITA i ANGLESITA. També es troben presents molts carbonats, que cementen les bretxes, com: ANQUERITA, CALCITA, DOLOMITA i SIDERITA.

Altres minerals presents són la BARITINA i el QUARS. Tot i l'abundor de minerals presents en aquest indret, cal recordar, que de tots ells, els explotats han estat l'ESFALERITA (per tal d'obtenir el Zn), i sobretot la GALENA (per tal de beneficiar el $\mathrm{Pb}$ i l'Ag). També cal dir, que de tots els minerals esmentats, possiblement els més abundants són els de plom, i en especial la galena; així com l'anquerita i la siderita, entre els carbonats.

PARADA 7 - CONDICIONAL. MINA RENÀLIA, (Terme municipal de Bellmunt de Priorat, comarca del Priorat). (Full 471).

Tot i que el recorregut haurà començat a la sortida de Falset, caldrà fer un recorregut d'uns $3 \mathrm{Km}$ i escaig, per la carretera local TP-7101 per tal d'anar cap a la població de Bellmunt del Priorat. Poc abans d'arribar-hi, ens caldrà agafar un camí per l'esquerra (just quan la carretera comença a baixar cap al poble). Aquest camí condueix 
cap a l'antiga Mina Renàlia (o Mina dels Alemans), per on farem aquesta primera aturada, si s'escau.

En aquest recorregut, primer hem tallat els materials granítics i granodiorítics d'edat carbonífera, situats dintre de la Serralada Prelitoral Catalana. Al respecte d'aquests granits, cal dir que es troben força alterats com a conseqüència dels processos de saulinitització.

La mina es relaciona amb unes mineralitzacions filonianes associades a una fractura que talla els materials paleozoics, tot i així es una mineralització de tipus "sed-ex". Entre els diferents minerals presents, cal fer esment de la GALENA i de l'ESFALERITA, així com molts dels que esmentarem a la propera aturada.

Cal fer esment de que en aquest indret es trobava un interessant "castellet", el qual constitueix part del nostre patrimoni miner. Possiblement és el millor conservat de l'extensa zona minera del Priorat, i creiem que cal tenir força cura de la seva conservació. A l'actualitat es troba a la plaça de la Mina Eugènia, on anirem a la propera aturada.

PARADA 8. INSTAL·LACIONS DE LA MINA REGIA I, i DE LA MINA REGIA II (O REGIA ANTIGA), (terme municipal de Bellmunt del Priorat, comarca del Priorat). (Full 471).

Des de la parada anterior, cal seguir cap al Molar, fins arribar a les instal-lacions de l'antiga Mina Regia, situades a la dreta del camí. En aquest indret, caldrà fer la present aturada, després d’haver recorregut 2-2’5 Km, més.

En ambdós mines hi ha mineralitzacions filonianes, fonamentalment de $\mathrm{Pb}-\mathrm{Zn}$, encaixades entre els porfirs granítics que tallen als materials carbonífers. Aquestes mineralitzacions es relaciones amb una important fractura, de direcció ENE-WSW. Així, sovint la mineralització te aspecte bretxoide.

Entre els minerals presents, cal fer esment dels següents: CALCOPIRITA, ESFALERITA, GALENA, MARCASSITA i PIRITA. Entre els minerals d'alteració es troben: GOETHITA (terrosa i limonítica), ATZURITA, CERUSSITA, HIDROCINCITA, MALAQUITA i ANGLESITA.

També es troben presents molts carbonats, que cementen les bretxes, com: ANQUERITA, CALCITA, DOLOMITA i SIDERITA. Altres minerals presents són la BARITINA i el QUARS. De tots ells, possiblement els més abundants són els de plom, (i en especial la galena); així com l'anquerita i la siderita, entre els carbonats. Tots ells es poden trobar fàcilment a les escombreres de la Mina Regia II.

Des d'aquest indret es pot observar clarament la discordança entre els materials triàsics del Serrat de la Roca (al Nord de la mina), i els materials paleozoics i granítics. Per d'altra banda, cap el NE es poden veure els nivells terciaris detrítics de la Serra del Montsant, amb la formació del mateix nom.

\section{AQUÍ FINALITZA EL RECORREGUT DE L'ITINERARI}




\section{BIBLIOGRAFIA}

GUIMERÀ, J. et altri (1992).- Geologia (II), Història Natural dels Països Catalans, Vol. 2, 547 pag. Enciclopedia catalana, S.A., Barcelona

IGME (1974a).- Mapa Geològico de España, a escala 1:50.000 (Segunda Série). Full i memòria no 471 (Mora d’Ebro). Ins. Tecnológico y GeoMinero de España. Minist. Indus. Energia. Madrid

IGME (1974b).- Mapa Geológico de España a Escala 1:50.000 (2a Sèrie). Full i Memòria $\mathrm{n}^{\circ} \underline{472}$ (Reus). Inst. Tecnológico y GeoMinero de España. Minist. Indus. Ener. Madrid

MATA-PERELLÓ, J.M. (1991).- Els Minerals de Catalunya Arxius de la Secció de Ciències, Vol XCIII, 444 pag. Institut d’Estudis Catalans, Barcelona

MATA-PERELLÓ, J.M. (1996).- Itinerari geològic i mineralògic pel Baix Camp i pel Priorat: des de l'Aleixar a Carnudella, Porrera i al Molar. Inèdit. 6 pàg. Manresa

MATA-PERELLÓ, J.M. (1997).- Recerca geològica i mineralògica per la comarca del Priorat: des de Cornudella a la Venta del Pobill, a Porrera i al Molar. Inèdit. 8 pàgines. Manresa

MATA-PERELLÓ, J.M. (1998a).- Recerca geològica i mineralògica per les comarques del Baix Camp i del Priorat: des de les Borges del cap al Molar. Inèdit, 14 pàgines. Manresa

MATA-PERELLÓ, J.M. (1998b).- Recorregut de recerca geològico-mineralògica i geoambiental per les comarques del Baix Camp i del Priorat: des de les Borges del cap al Molar per Pradell de la Teixeta. Inèdit, 18 pàgines. Manresa.

MATA-PERELLÓ, J.M. (1998c).- Recorregut de recerca geològica i mineralògica per les comarques del Baix Camp i del Priorat: des de l'Aleixar al Mas del Mestre, i des del Coll de la Teixeta al Coll de Falset i al Molar. Algeps, sèrie B, $\mathrm{n}^{\circ} 125,16$ pàgines. Manresa

MATA-PERELLÓ, J.M. (1999).- Recerca geològica i mineralògica per les comarques del Baix Camp i del Priorat: des de les Borges del Camp a Pradell de la Teixeta i al Molar. Algeps, sèrie $B, n^{\circ} 125,16$ pàgines. Manresa

MATA-PERELLÓ, J.M. (2000a).- Recorregut de recerca geològica i mineralògica per les comarques del Baix Camp, de la Ribera d'Ebre i del Priorat: des de Reus a Mont-roig del Camp, a Tivissa i a Falset. Xaragall, sèrie B, $\mathrm{n}^{\circ}$ 129, 12 pàgines. Manresa

MATA-PERELLÓ, J.M. (2000b).- Recorregut de recerca geològica i mineralògica per les comarques del Baix Camp i del Priorat: des de Reus a Escornalbou i l'Argentera, i del Coll de la Teixeta al Coll de Falset i al Molar. Xaragall, sèrie B, $\mathrm{n}^{0}$ 133, 18 pàgines. Manresa 
MATA-PERELLÓ, J.M. (2001).- Recorregut de recerca geològica i mineralògica per les comarques del Baix Camp i del Priorat: des del Coll de la Teixeta al Coll de Falset a Bellmunt del Priorat i al Molar. Algeps, sèrie B, $n^{\circ}$ 194, 15 pàgines. Manresa

MATA-PERELLÓ, J.M. (2002).- Recorregut de recerca geològica i mineralògica a través del patrimoni miner de la comarca del Priorat: des de Bellmunt del Priorat al Molar. Inedit, 10 pàgines. Manresa

MATA - PERELLÓ, J.M. (2004).- Recorregut de recerca geològica i mineralògica per la comarca del Priorat, a través del seu patrimoni miner: des de Pradell de la Teixeta a Falset i al Molar. Inèdit. 13 pag. Manresa

MATA - PERELLÓ, J.M. (2007).- Recorregut de recerca geològica i mineralògica per les comarques del Baix Camp i del Priorat: des de les Borges del Camp cap a Riudecanyes, l'Argentera, Duesaigües, al Coll de la Teixeta i a Bellmunt del Priorat. Inèdit. 12 págines. Manresa

MATA - PERELLÓ, J.M. (2008a).- Recorregut de recerca geològica i mineralògica a través de la comarca del Priorat: des de Marçà cap a Bellmunt del Priorat, el Molar i cap a la Figuera de Falset. Inèdit. 12 págines. Manresa

MATA - PERELLÓ, J.M. (2008b).- Recorregut de recerca geològica i mineralògica per la comarca del Priorat: des del Coll de la Teixeta a Falset i a Bellmunt del Priorat. Inèdit. 12 pàgines. Manresa

MATA-PERELLÓ, J.M. i COLLDEFORNS, B. (1994). Selecció d'itineraris geològics i mineralògics per les comarques del Baix Camp, Conca de Barberà, Priorat i Ribera d’Ebre. Xaragall, ${ }^{\circ}$ 28, 36 pàgines. Mamresa

MELGAREJO I DRAPER J.C. (1992).- Estudio geológico y metalogenético del paleozoico del sur de las Cordilleras Costeras Catalanas. Memórias del Instituto Tecnológico y Geo-Minero de España , tomo 103, 605 páginas. Madrid

RIBA ARDERIU, O. Et altri. (1976).- Geografia física dels Països Catalans. Edit Ketres, 205 pàgines. Barcelona 